\title{
Investigation on the stability, electronic, optical and mechanical properties of novel calcium carbonate hydrates via first-principles calculations
}

\author{
Yunxuan Zhou ${ }^{1}$, Mingyu $\mathrm{Hu}^{2}$, Gengsen $\mathrm{Xu}^{3}$, Ruiju $\mathrm{Xu}^{3}$, Xiaoyu Chong ${ }^{4}$, and Jing Feng ${ }^{3}$ \\ ${ }^{1}$ Kunming University of Science and Technology, \\ ${ }^{2}$ Faculty of Materials Science and Engineering, Kunming University of Science and \\ Technology \\ ${ }^{3}$ Kunming University of Science and Technology \\ ${ }^{4}$ Pennsylvania State University
}

May 5, 2020

\begin{abstract}
Calcium carbonate $(\mathrm{CaCO} 3)$ is an inorganic compound which is widely used in industry, chemistry, construction, ocean acidification and biomineralization due to its rich constituent on earth and excellent performance, in which calcium carbonate hydrates are important systems. In Z.Y. Zou et al's work (Science, 2019, 363, 396-400), they found a novel calcium carbonate hemihydrate phase, but the structure stability, optical and mechanical properties has not been studied. In this work, the stability, electronic, optical, and mechanical properties of novel calcium carbonate hydrates were investigated by using the first-principles calculations within density functional theory (DFT). CaCO3 $x H 2 O(x=1 / 2,1$ and 6$)$ are determined dynamically stable phases by phonon spectrum, but the Gibbs energy of reaction of $\mathrm{CaCO} 3 \cdot 1 / 2 \mathrm{H} 2 \mathrm{O}$ is higher than other calcium carbonate hydrates. That's why the CaCO3.1/2H2O is hard to synthesize in the experiments. In addition, the optical and mechanical properties of $\mathrm{CaCO} 3 \cdot \mathrm{xH} 2 \mathrm{O}(\mathrm{x}=1 / 2,1$ and 6$)$ are expounded in detail. It shows that the $\mathrm{CaCO} \cdot 1 / 2 \mathrm{H} 2 \mathrm{O}$ has the largest bulk modulus, shear modulus, Young's modulus with the values $60.51,36.56$ and $91.28 \mathrm{GPa}$ with respect to other two calcium carbonate hydrates investigated in this paper. This work will provide guidance for experiments and its applications, such as biomineralization, geology, and industrial processes.
\end{abstract}

\section{Hosted file}

Manuscript of CaC03--INT J QUANTUM CHEM.docx available at https://authorea.com/users/ 288942/articles/414674-investigation-on-the-stability-electronic-optical-and-mechanicalproperties-of-novel-calcium-carbonate-hydrates-via-first-principles-calculations

\section{Figures caption}

Fig. 1. The crystal structure of calcium carbonate hydrates;(a) $\mathrm{CaCO}_{3} \cdot 1 / 2 \mathrm{H}_{2} \mathrm{O}$; (b) $\mathrm{CaCO}_{3} \cdot 6 \mathrm{H}_{2} \mathrm{O}$; (c) $\mathrm{CaCO}_{3} \cdot \mathrm{H}_{2} \mathrm{O}$; (d) The calculated X-ray diffraction of calcium carbonate hydrates, (e) the calculated X-ray diffraction of $\mathrm{CaCO}_{3} \cdot 1 / 2 \mathrm{H}_{2} \mathrm{O}$ and experimental values by Z.Y. Zou et al[8]

Fig. 2. Phonon dispersion of calcium carbonate hydrates; (a) (b) $\mathrm{CaCO}_{3} \cdot 1 / 2 \mathrm{H}_{2} \mathrm{O}$; (c) (d) $\mathrm{CaCO}_{3} \cdot 6 \mathrm{H}_{2} \mathrm{O}$; (e) (f) $\mathrm{CaCO}_{3} \cdot \mathrm{H}_{2} \mathrm{O}$, the green hollow dots represent experimental values by Z.Y. Zou et al [8] 
Fig. 3. Band structure and partial density of states of calcium carbonate hydrates; (a) (b) $\mathrm{CaCO}_{3} \cdot 1 / 2 \mathrm{H}_{2} \mathrm{O}$; (c) (d) $\mathrm{CaCO}_{3} \cdot 6 \mathrm{H}_{2} \mathrm{O}$; (e) (f) $\mathrm{CaCO}_{3} \cdot \mathrm{H}_{2} \mathrm{O}$

Fig. 4. The electric density distribution (a), (c) and (e) and differences of charge density distribution; (b), (d) and (f) for calcium carbonate hydrates on the (100) plane; top: $\mathrm{CaCO}_{3} \cdot \mathrm{H}_{2} \mathrm{O}$; middle: $\mathrm{CaCO}_{3} \cdot 6 \mathrm{H}_{2} \mathrm{O}$; bottom: $\mathrm{CaCO}_{3} \cdot 1 / 2 \mathrm{H}_{2} \mathrm{O}$

Fig.5. The optical properties of calcium carbonate hydrates; (a) Dielectric function; (b) Reflectivity; (c) Conductivity; (d)Absorption; (e) Refractive index; (f) Loss function.

Fig. 6. Contour plots of the Young's modulus of calcium carbonate hydrates in $3 \mathrm{D}$ space. (a) $\mathrm{CaCO}_{3} \cdot 1 / 2 \mathrm{H}_{2} \mathrm{O}$; (b) $\mathrm{CaCO}_{3} \cdot 6 \mathrm{H}_{2} \mathrm{O}$; (c) $\mathrm{CaCO}_{3} \cdot \mathrm{H}_{2} \mathrm{O}$; (d) Planar projections of the Young's modulus of calcium carbonate hydrates on the (001), (e) (110) crystallographic planes.

Figure S1. The calculated Mulliken's overlap population of calcium carbonate hydrates.

(a) $\mathrm{CaCO}_{3} \cdot 1 / 2 \mathrm{H}_{2} \mathrm{O}$; (b) $\mathrm{CaCO}_{3} \cdot 6 \mathrm{H}_{2} \mathrm{O}$; (c) $\mathrm{CaCO}_{3} \cdot \mathrm{H}_{2} \mathrm{O}$.

Fig S2.The calculated (a) average bond length $(L(\mathrm{AB})(\AA))$ and (b) the mean bond population $(n(\mathrm{AB})(\mathrm{e}))$ of calcium carbonate hydrates

Fig. S3. The variations of the elastic moduli (Bulk $(B)$, Shear $(G)$ and Young moduli $(E)$ ) value and Poisson's ratio of calcium carbonate hydrates with different volume.

\section{Hosted file}

Figs of $\mathrm{CaCO} 3$--INT J QUANTUM CHEM.docx available at https://authorea.com/users/288942/ articles/414674-investigation-on-the-stability-electronic-optical-and-mechanicalproperties-of-novel-calcium-carbonate-hydrates-via-first-principles-calculations

\section{Hosted file}

Tables of CaCO3 --INT J QUANTUM CHEM.docx available at https://authorea.com/users/288942/ articles/414674-investigation-on-the-stability-electronic-optical-and-mechanicalproperties-of-novel-calcium-carbonate-hydrates-via-first-principles-calculations 